\title{
Phytochemical Analysis of Agrimonia pilosa Ledeb, Its Antioxidant Activity and Aldose Reductase Inhibitory Potential
}

\author{
Set Byeol Kim ${ }^{1,+}$, Seung Hwan Hwang ${ }^{1,+}$, Hong-Won Suh ${ }^{2}$ and Soon Sung Lim 1,2,* \\ 1 Department of Food Science and Nutrition, Hallym University, 1 Hallymdaehak-gil, Chuncheon, \\ Gangwon-do 24252, Korea; jwsbcb0187@naver.com (S.B.K.); isohsh@gmail.com (S.H.H.) \\ 2 Institute of Natural Medicine, College of Medicine, Hallym University, 1 Hallymdaehak-gil, Chuncheon, \\ Gangwon-do 24252, Korea; hwsuh@hallym.ac.kr \\ * Correspondence: limss@hallym.ac.kr; Tel.: +82-33-248-2133; Fax: +82-33-251-0663 \\ + These authors contributed equally to this work.
}

Academic Editor: Toshio Morikawa

Received: 23 December 2016; Accepted: 6 February 2017; Published: 10 February 2017

\begin{abstract}
The aim of this study was to determine aldose reductase (AR) inhibitory activity and 1,1-diphenyl-2-picrylhydrazyl (DPPH) free radical scavenging activity of compounds from Agrimonia pilosa Ledeb (AP). We isolated agrimoniin (AM), four flavonoid glucosides and two flavonoid glucuronides from the $n$-butanol fraction of AP 50\% methanol extract. In addition to isolated compounds, the AR-inhibitory activity and the DPPH free radical scavenging activity of catechin, 5-flavonoids, and 4-flavonoid glucosides (known components of AP) against rat lens AR (RLAR) and DPPH assay were measured. AM showed $\mathrm{IC}_{50}$ values of 1.6 and $13.0 \mu \mathrm{M}$ against RLAR and DPPH scavenging activity, respectively. Additionally, AM, luteolin-7-O-glucuronide (LGN), quercitrin (QU), luteolin (LT) and afzelin (AZ) showed high inhibitory activity against AR and were first observed to decrease sorbitol accumulation in the rat lens under high-sorbitol conditions ex vivo with inhibitory values of $47.6 \%, 91.8 \%, 76.9 \%, 91.8 \%$ and $93.2 \%$, respectively. Inhibition of recombinant human AR by AM, LGN and AZ exhibited a noncompetitive inhibition pattern. Based on our results, AP and its constituents may play partial roles in RLAR and oxidative radical inhibition. Our results suggest that AM, LGN, QU, LT and AZ may potentially be used as natural drugs for treating diabetic complications.
\end{abstract}

Keywords: Agrimonia pilosa Ledeb; aldose reductase; flavonoids; 1,1-diphenyl-2-picrylhydrazyl (DPPH); diabetic complication

\section{Introduction}

Aldose reductase (AR, EC.1.1.1.21) is a key enzyme in the polyol pathway that catalyzes the conversion of glucose to sorbitol in the hyperglycemic state and oxidoreductase-induced nicotinamide adenine dinucleotide phosphate (NADPH) to $\mathrm{NADP}^{+}$[1]. Accumulation of sorbitol leads to the generation of osmotic stress, an influx of water and causes of diabetic complications such as cataracts and retinopathy. In addition, the conversion of sorbitol to fructose is catalyzed by nicotinamide adenine dinucleotide (NADH)-dependent sorbitol dehydrogenase. Increased fructose formation leads to the formation of reactive dicarbonyl species such as glucosones, glyoxal, and methylglyoxal, which are important factors in advanced glycation end products [2]. Oxidative stress causes an imbalance between the formation of free radicals and the body's antioxidant potential. Free radicals are defined as atoms or molecules that contain one or more unpaired electrons [3]. Diabetes mellitus and its complications, such as retinopathy, nephropathy, neuropathy, and atherosclerosis, are caused by an 
imbalance in cells and free radicals, and this imbalance is mainly responsible for the auto-oxidation of glucose and glycosylated proteins $[4,5]$ Therefore, the development of diabetic complications could be controlled by inhibiting AR activity and also by increasing antioxidant activity in the body.

Agrimonia pilosa Ledeb (A. pilosa, AP), belonging to the Rosaceae family, is famous in traditional Chinese medicine. According to pharmacological studies, it has anti-nociceptive, anti-inflammatory, antioxidant, anticancer and $\alpha$-glucosidase inhibitory activity [6,7]. The known constituents of AP are 3-methoxy quercetin, quercitrin $(\mathrm{QU})$, quercetin $(\mathrm{QC})$, tiliroside, ursolic acid, tormentic acid and corosolic acid [8,9]. The major known flavonoids of AP are catechin (CT), luteolin (LT), QC, isoquercetin (IQC), hyperin (HP), apigenin (AG), vitexin (VT), kaempferol (KP), astragalin (AS), and afzelin (AZ) [10-12]. Generally, these flavonoids are involved in plant metabolism and possess antioxidant, antidiabetic, anticancer, and various inhibitory activities $[13,14]$.

The isolation and purification of active compounds from complex plant extracts takes a long time. In the past few years, several online high performance liquid chromatography (HPLC) methods that use post-column derivative method, which are based on online detection by 1,1-diphenyl-2-picrylhydrazyl (DPPH) or 2,2'-azino-bis(3-ethylbenzothiazoline-6-sulphonic acid) (ABTS) radicals, have been utilized to screen antioxidants in some complex plant extracts to avoid the aforementioned problem. These methods required an online instrumental system and technical skills that were complex and available. Recently, the more convenient offline DPPH-HPLC method was successfully developed by spiking the complex plant extracts $[15,16]$.

To date, no data have been published on the inhibitory effects of AP on rat lens AR (RLAR), DPPH radical scavenging capacity and offline DPPH-HPLC assay. Therefore, the inhibitory effects of ten known flavonoids from the literature as well as seven compounds isolated from AP 50\% methanol $(\mathrm{MeOH})$ extract (APE) were investigated to evaluate their use in treatment of RLAR-related diabetic complications. The active compounds of APE that showed antioxidant properties were investigated by offline DPPH-HPLC assay. Additionally, the ability of the major active compounds to decrease sorbitol accumulation in rat lens in ex vivo high-sorbitol conditions as well as the recombinant human AR (RHAR) inhibition type of the compounds were assessed.

\section{Results}

\subsection{Structural Determination of Isolated Compounds}

The effects of APE on RLAR and DPPH free radical scavenging activity were further investigated. APE exhibited inhibitory activity against RLAR, with $51.4 \%$ inhibition at a concentration of $10.0 \mu \mathrm{g} / \mathrm{mL}$. Moreover, APE showed 53.4\% inhibition of DPPH at a concentration of $7.1 \mu \mathrm{g} / \mathrm{mL}$. Consequently, APE was further partitioned by systematic fractionation. Among the resulting fractions, the ethyl acetate (EtOAc) and $n$-butanol $(n$-BuOH)-soluble fractions exhibited potent inhibitory activity against RLAR with $84.4 \%$ and $92.4 \%$ inhibition, respectively, compared with the positive control tetramethylene glutaric acid (TMG; 99.7\% inhibition) at a concentration of $1.0 \mu \mathrm{g} / \mathrm{mL}$. The EtOAc and $n-\mathrm{BuOH}$ fractions also showed inhibitory activity against $\mathrm{DPPH}$, with $62.3 \%$ and $61.0 \%$ inhibition, respectively, compared with the positive control L-ascorbic acid (81.0\% inhibition) (Table 1).

Therefore, this study focused on the isolation of the AR inhibitor from the $n$ - $\mathrm{BuOH}$ fraction. The seven compounds isolated from $n$ - $\mathrm{BuOH}$ were identified as compound 1 (agrimoniin, $\mathrm{AM}$, $69.3 \mathrm{mg}$ ) [17], compound 2 (rutin, RT, $30.3 \mathrm{mg}$ ) [18], compound 3 (luteolin-7-O-glucoside, LGC, $96.1 \mathrm{mg}$ ) [19], compound 4 (luteolin-7-O-glucuronide, LGN, $150.5 \mathrm{mg}$ ) [20], compound 5 (quercitrin, QU, $11.6 \mathrm{mg}$ ) [21], compound 6 (apigenin-7-O-glucoside, AGC, $21.3 \mathrm{mg}$ ) [22] and compound 7 (apigenin-7-O-glucuronide, AGN, $251.6 \mathrm{mg}$ ) [23] on the basis of the 1D and 2D NMR spectral data (Table S1), as well as by comparison with published spectral data (Figures 1 and 2). 
Table 1. Inhibitory effect of 50\% $\mathrm{MeOH}$ extract of Agrimonia pilosa Ledeb. on rat lens aldose reductase (RLAR) and 1,1-diphenyl-2-picrylhydrazyl (DPPH) free radical scavenging activity. TMG: tetramethylene glutaric acid.

\begin{tabular}{cccc}
\hline \multirow{2}{*}{ Extract and Fractions } & \multicolumn{2}{c}{ Inhibition (\%) } \\
\cline { 3 - 4 } & & RLAR & DPPH \\
\hline \multicolumn{2}{c}{ Methylene chloride extract } & $6.8 \pm 0.20$ & $4.19 \pm 0.14$ \\
\hline \multirow{2}{*}{$50 \% \mathrm{MeOH}$ ext. } & Crude extract & $51.4 \pm 0.10$ & $53.4 \pm 0.14$ \\
& EtOAc fraction & $84.4 \pm 0.27$ & $62.3 \pm 0.04$ \\
& $n$-BuOH fraction & $92.4 \pm 0.14$ & $61.0 \pm 0.42$ \\
& Water fraction & $37.9 \pm 0.47$ & $33.0 \pm 0.10$ \\
\hline RLAR & TMG & $99.7 \pm 0.11$ & - \\
\hline DPPH & Ascorbic acid & - & $81.0 \pm 0.01$ \\
\hline
\end{tabular}<smiles>O=C(OCC1C(OC(=O)c2cc(O)c(O)c(O)c2O)OC(OC(=O)c2cc(O)c(O)c(O)c2O)C(OC(=O)c2cc(O)c(O)c(O)c2-c2c(O)c(O)c(O)c(O)c2O)C1OC(=O)c1cc(O)c(O)c(O)c1O)c1cc(O)c(O)c(O)c1O</smiles><smiles>O=C(OC1OC2COC(=O)c3cc(O)c(O)c(O)c3C(OC(=O)c3cc(O)c(O)c(O)c3-c3c(O)c(O)c(O)c(O)c3-c3c2cc(O)c(O)c3O)C1OC(=O)c1cc(O)c(O)c(O)c1O)c1cc(O)c(O)c(I)c1</smiles><smiles>Oc1cc(O)c2c(c1)O[C@H](c1ccc(O)c(O)c1)[C@H](O)C2</smiles>

(+)-Catechin

Agrimoniin (1)<smiles>[R]c1cc(-c2oc3c([R])c([R])cc(O)c3c(=O)c2[R])ccc1O</smiles>

Flavonoid derivatives

\begin{tabular}{|c|c|c|c|c|c|}
\hline No. & Compound name & $\mathbf{R}_{1}$ & $\mathbf{R}_{2}$ & $\mathbf{R}_{3}$ & $\mathbf{R}_{4}$ \\
\hline \multirow{6}{*}{$\mathrm{IC}^{\mathrm{a})}$} & Rutin & $\mathrm{OH}$ & $\begin{array}{c}-O-\alpha \text {-L-rhamnopyranosyl- }(1 \rightarrow 6) \\
-\beta \text {-D-glucopyranose }\end{array}$ & $\mathrm{OH}$ & $\mathrm{H}$ \\
\hline & Luteolin-7-O-glucoside & -O- $\beta$-D-glucopyranose & $\mathrm{H}$ & $\mathrm{OH}$ & $\mathrm{H}$ \\
\hline & Luteolin-7-O-glucuronide & $-O-\beta$-D-glucopyranosiduronic acid & $\mathrm{H}$ & $\mathrm{OH}$ & $\mathrm{H}$ \\
\hline & Quercitrin & $\mathrm{OH}$ & $-O$ - $\alpha$-L-rhamnopyranose & $\mathrm{OH}$ & $\mathrm{H}$ \\
\hline & Apigenin-7-O-glucoside & $-O-\beta$-D-glucopyranose & $\mathrm{H}$ & $\mathrm{H}$ & $\mathrm{H}$ \\
\hline & Apigenin-7-O-glucuronide & $-O-\beta$-D-glucopyranosiduronic acid & $\mathrm{H}$ & $\mathrm{H}$ & $\mathrm{H}$ \\
\hline \multirow{9}{*}{$\mathrm{KNC}^{\mathrm{b})}$} & Luteolin & $\mathrm{OH}$ & $\mathrm{H}$ & $\mathrm{OH}$ & $\mathrm{H}$ \\
\hline & Quercetin & $\mathrm{OH}$ & $\mathrm{OH}$ & $\mathrm{OH}$ & $\mathrm{H}$ \\
\hline & Isoquercitrin & $\mathrm{OH}$ & -O- $\beta$-D-glucopyranose & $\mathrm{OH}$ & $\mathrm{H}$ \\
\hline & Hyperin & $\mathrm{OH}$ & -O- $\beta$-D-galactopyranose & $\mathrm{OH}$ & $\mathrm{H}$ \\
\hline & Apigenin & $\mathrm{OH}$ & $\mathrm{H}$ & $\mathrm{H}$ & $\mathrm{H}$ \\
\hline & Vitexin & $\mathrm{OH}$ & $\mathrm{H}$ & $\mathrm{H}$ & $-C-\beta$-D-glucopyranose \\
\hline & Kaempferol & $\mathrm{OH}$ & $\mathrm{OH}$ & $\mathrm{H}$ & $\mathrm{H}$ \\
\hline & Astragalin & $\mathrm{OH}$ & $-O-\beta$-D-glucopyranose & $\mathrm{H}$ & $\mathrm{H}$ \\
\hline & Afzelin & $\mathrm{OH}$ & $-O$ - $\alpha$-L-rhamnopyranose & $\mathrm{H}$ & $\mathrm{H}$ \\
\hline
\end{tabular}

Figure 1. The structure of the compounds known and isolated from the $n-\mathrm{BuOH}$ fraction of $A$. pilosa Ledeb; $^{\text {a) }} \mathrm{IC}$ is the compounds isolated from A. pilosa Ledeb; ${ }^{\text {b) }} \mathrm{KNC}$ is the known compounds isolated from A. pilosa Ledeb. 


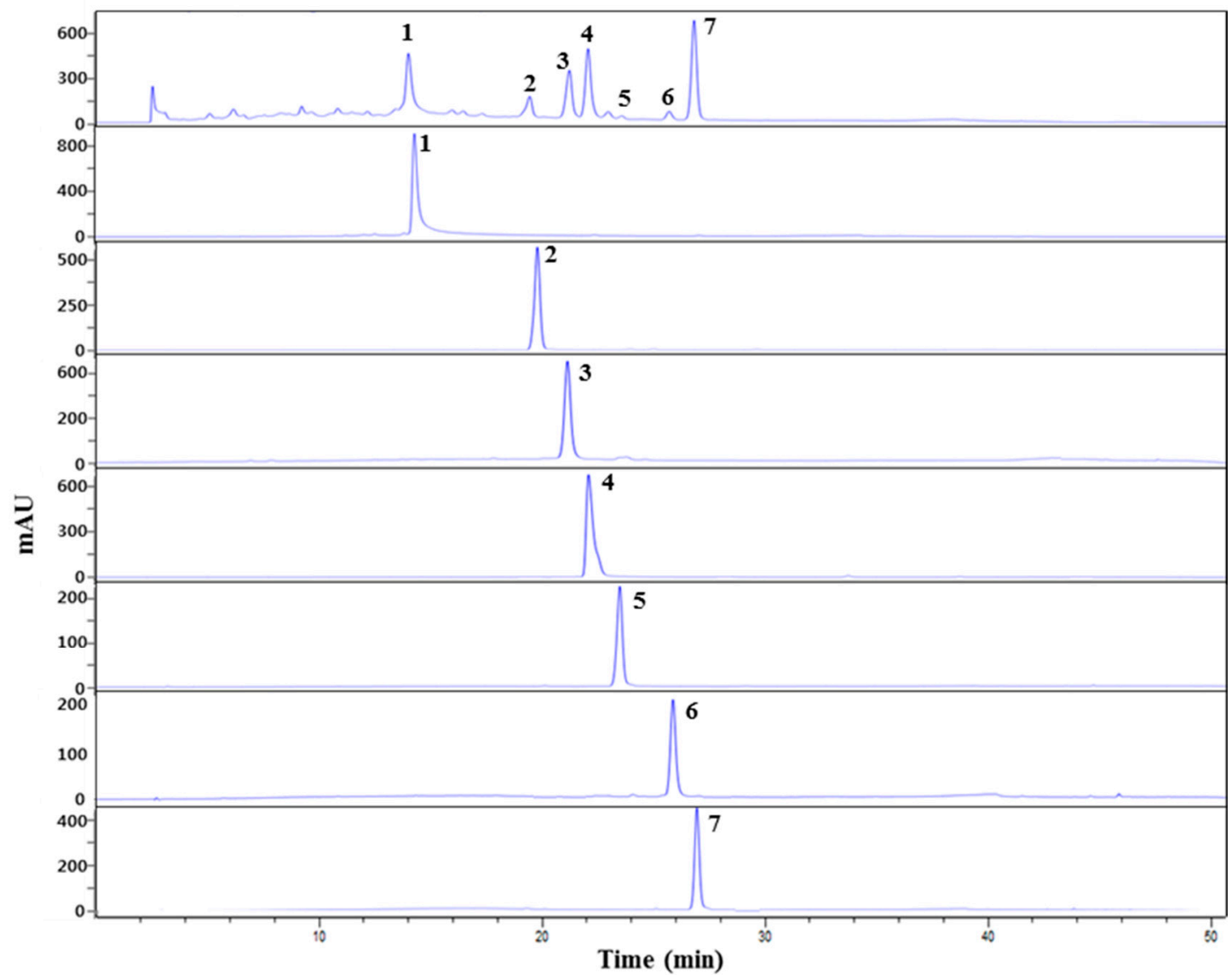

Figure 2. HPLC chromatogram of the compounds isolated from the $n$ - $\mathrm{BuOH}$ fraction of A. pilosa Ledeb. at $254 \mathrm{~nm}$; Peak 1: agrimoniin; Peak 2: rutin; Peak 3: luteolin-7-O-glucoside; Peak 4: luteolin-7-O-glucuronide; Peak 5: quercitrin; Peak 6: apigenin-7-O-glucoside; Peak 7: apigenin-7-O-glucuronide.

\subsection{Inhibitory Effect of Isolated Compounds on RLAR}

We compared the ability of the isolated compounds and TMG (a positive control) to inhibit RLAR activity (Table 2). Among the isolated constituents, RT, LGC and AGC exhibited RLAR inhibitory activity, with $50 \%$ inhibition concentration ( $\mathrm{IC}_{50}$ ) values of $9.5,8.1$ and $4.3 \mu \mathrm{M}$, respectively. QU had the highest $\mathrm{IC}_{50}$ value of $0.2 \mu \mathrm{M}$, which was 2.5 times higher than the positive control $\left(\mathrm{IC}_{50}\right.$ of $\mathrm{TMG}=0.5 \mu \mathrm{M})$. AM and LGN had high $\mathrm{IC}_{50}$ values at 1.6 and $0.7 \mu \mathrm{M}$, respectively, while AGN was inactive. In addition, previous investigations of flavonoids isolated from AP by Jiang et al., Kato et al., and Liu et al. reported that CT, LT, QC, IQC, HP, AG, VT, KP, AS, and AZ were isolated from the leaves of AP [10-12]. The RLAR inhibitory effects of ten known compounds were evaluated using TMC as a positive control. LT and AZ had the strongest RLAR inhibitory activity, with $\mathrm{IC}_{50}$ values of 0.6 and $1.0 \mu \mathrm{M}$, respectively. QC, IOC, HP, AG and AS also exhibited potent inhibitory activity, with $\mathrm{IC}_{50}$ values ranging from 3.2 to $15.2 \mu \mathrm{M}$. CT and VT showed lower inhibitory activity, with $7.2 \%$ and $12.2 \%$ inhibition, respectively, against RLAR at a concentration of $10.0 \mu \mathrm{g} / \mathrm{mL}$. The RLAR inhibitory effect of ten known compounds was similar to previous data from the literature [24,25]. 
Table 2. Inhibitory effect of compounds referenced and isolated from A. pilosa Ledeb. on rat lens aldose reductase (RLAR) and DPPH free radical scavenging activity.

\begin{tabular}{|c|c|c|c|c|c|}
\hline \multirow{3}{*}{ Entry } & \multirow{3}{*}{ Compounds } & \multicolumn{2}{|c|}{ DPPH } & \multicolumn{2}{|c|}{ RLAR } \\
\hline & & \multicolumn{3}{|c|}{ Experiments } & \multirow{2}{*}{$\begin{array}{c}\text { Reference } \\
\mathrm{IC}_{50}(\mu \mathrm{M}) \\
\end{array}$} \\
\hline & & $\mathrm{IC}_{50}(\mu \mathrm{M})$ & Inhibition (\%) & $\mathrm{IC}_{50}(\mu \mathrm{M})$ & \\
\hline \multirow{7}{*}{$\mathrm{IC}^{\mathrm{a})}$} & Agrimoniin (AM) & $13.0 \pm 0.06$ & $35.0 \pm 0.41$ & $1.6 \pm 0.12$ & - \\
\hline & Rutin (RT) & $66.8 \pm 0.34$ & $31.7 \pm 0.65$ & $9.5 \pm 0.75$ & $9.0[24]^{b)}$ \\
\hline & Luteolin-7-O-glucoside (LGC) & $71.5 \pm 0.29$ & $46.9 \pm 0.95$ & $8.1 \pm 0.72$ & $7.5[26]$ \\
\hline & Luteolin-7-O-glucuronide (LGN) & $80.6 \pm 0.38$ & $83.3 \pm 0.88$ & $0.7 \pm 0.54$ & $3.1[27]$ \\
\hline & Apigenin-7-O-glucoside (AGC) & $>250$ & $40.2 \pm 0.56$ & $4.3 \pm 0.14$ & $23.0[28]$ \\
\hline & Quercitrin (QU) & $77.9 \pm 0.27$ & $97.4 \pm 1.38$ & $0.2 \pm 0.02$ & $0.2[29]$ \\
\hline & Apigenin-7-O-glucuronide (AGN) & $>250$ & $<0$ & $>30$ & - \\
\hline \multirow{10}{*}{$\mathrm{KNC}^{\mathrm{b})}$} & Catechin (CT) & $106.7 \pm 0.43$ & $7.2 \pm 1.02$ & $>30$ & $>30[24]$ \\
\hline & Kaempferol (KP) & $91.6 \pm 0.68$ & $11.8 \pm 0.81$ & $15.2 \pm 1.32$ & $10[24]$ \\
\hline & Quercetin (QC) & $70.4 \pm 0.15$ & $74.1 \pm 0.85$ & $3.2 \pm 0.13$ & $2.2[24]$ \\
\hline & Isoquercitrin (IQC) & $65.9 \pm 0.46$ & $41.0 \pm 1.07$ & $5.1 \pm 0.88$ & $4.5[24]$ \\
\hline & Hyperin (HP) & $73.3 \pm 0.23$ & $90.8 \pm 0.96$ & $4.1 \pm 0.32$ & $3.0[24]$ \\
\hline & Apigenin (AG) & $156.3 \pm 1.21$ & $81.8 \pm 1.20$ & $3.2 \pm 0.21$ & $2.2[24]$ \\
\hline & Vitexin (VT) & $>250$ & $12.2 \pm 0.95$ & $>30$ & $>30[25]$ \\
\hline & Astragalin (AS) & $>250$ & $53.3 \pm 1.14$ & $5.1 \pm 0.89$ & $>30[25]$ \\
\hline & Luteolin (LT) & $88.2 \pm 0.52$ & $80.2 \pm 0.90$ & $0.6 \pm 0.03$ & $0.5[27]$ \\
\hline & Afzelin (AZ) & $>250$ & $86.2 \pm 0.38$ & $1.0 \pm 0.27$ & $0.3[30]$ \\
\hline \multirow{2}{*}{$\begin{array}{l}\text { Positive } \\
\text { control }\end{array}$} & $\begin{array}{l}\text { L-Ascorbic } \\
\text { acid }\end{array}$ & $147.3 \pm 0.43$ & - & - & - \\
\hline & RLAR & - & $119.7 \pm 0.22$ & $0.5 \pm 0.05$ & $1.0[30]$ \\
\hline
\end{tabular}

a) ICs are the compounds isolated from A. pilosa Ledeb; ${ }^{\text {b) }} \mathrm{KNCs}$ are the known compounds isolated from $A$. pilosa Ledeb; ${ }^{b)}$ [Number] is reference number.

\subsection{DPPH and Off-Line DPPH HPLC Assay}

The $n-\mathrm{BuOH}$ fraction showed high DPPH radical scavenging activity. The chromatogram of the $n$-BuOH fraction without DPPH (blue line) and with DPPH (red line) is shown in Figure 3A, which presents the peak areas of seven compounds isolated reduced obviously. As shown in Figure 3B, seven compounds showed peak area reduction (PAR) between $13.6 \%-37.4 \%$. In addition, Zeng et al. reported that the rear eluting peak of the 34-min retention time is of DPPH [15]. Among these seven compounds, AM and QU (PAR 23\%-37\%) would be more potent antioxidants than RT, LGC, LGN, AGC and AGN, which showed PAR lower than $20.0 \%$. The results of seven compounds in $n$-BuOH fraction suggested antioxidant activity. The scavenging activity of the seven compounds isolated from the $n-\mathrm{BuOH}$ fraction of APE was evaluated by measuring DPPH free radical scavenging activity (Table 3). Of the tested compounds, $\mathrm{AM}$ had the highest $\mathrm{IC}_{50}$ value at $13.0 \mu \mathrm{M}$. RT, LGC, LGN and QU also showed strong scavenging activity with $\mathrm{IC}_{50}$ values of $66.8-80.6 \mu \mathrm{M}$, compared to the positive control, L-ascorbic acid $\left(\mathrm{IC}_{50}=147.3 \mu \mathrm{M}\right)$. However, AGC and AGN had almost no DPPH free radical scavenging activity. Scavenging activity of the known compounds from AP was evaluated using L-ascorbic acid. Of the tested known compounds, LT, QC, IOC, HP, and KP showed strong scavenging activity, with $\mathrm{IC}_{50}$ values of 88.2, 70.4, 65.9, 73.3, and $91.6 \mu \mathrm{M}$, respectively, which were higher than those of the positive control (L-ascorbic acid $=147.3 \mu \mathrm{M}$ ). On the other hand, VT, AS, and AZ showed no DPPH free radical scavenging activity. 

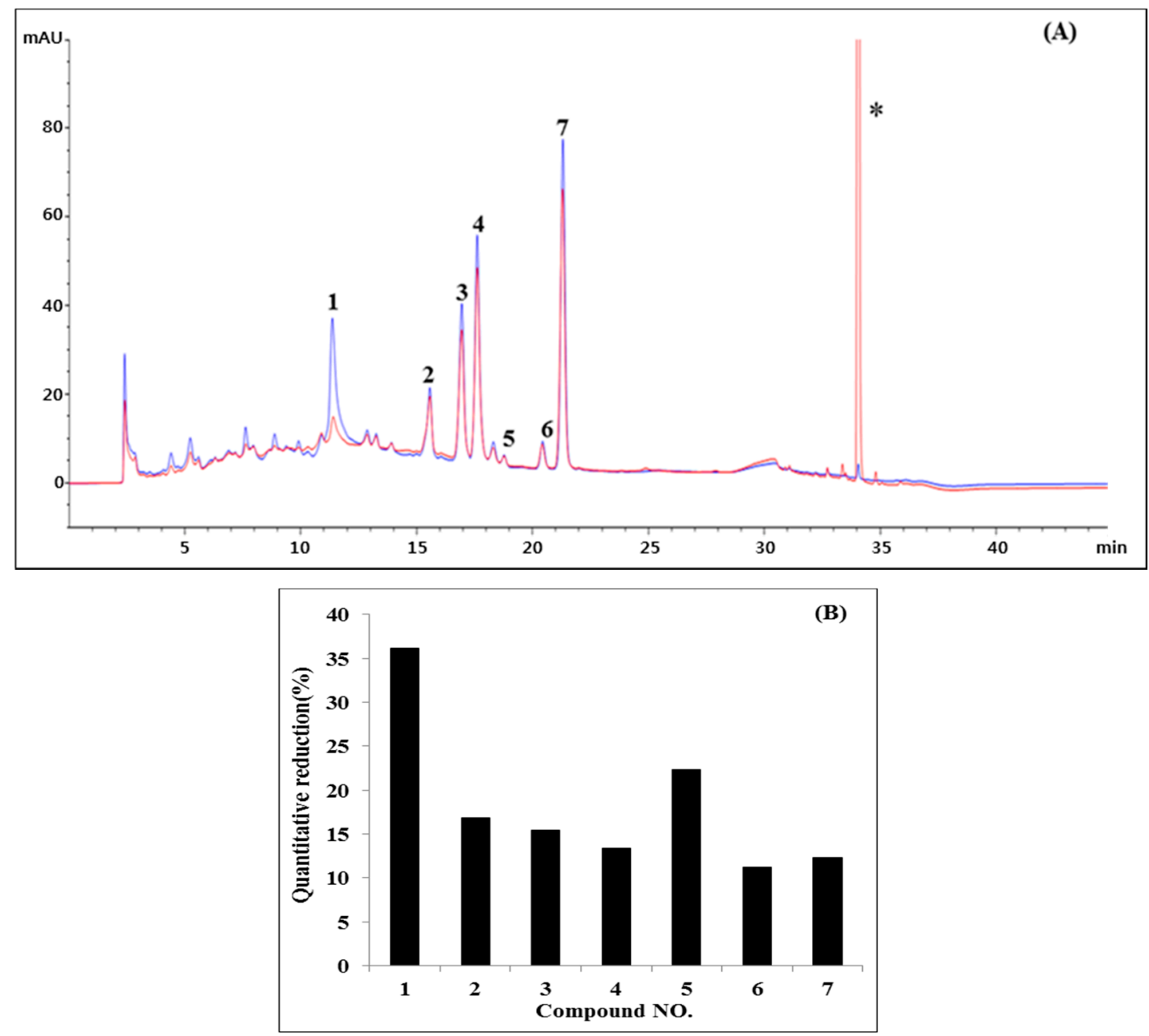

Figure 3. HPLC-ultraviolet (UV) (before reaction: blue) and DPPH-HPLC-UV (after reaction: red) of the $n-\mathrm{BuOH}$ fraction from A. pilosa Ledeb. at $254 \mathrm{~nm}$ (A) and quantitative reduction (\%) in the peak areas of compounds designated as follows (B); Peak 1: Agrimoniin; Peak 2: Rutin; Peak 3: Luteolin-7-O-glucoside; Peak 4: Luteolin-7-O-glucuronide; Peak 5: Quercitrin; Peak 6: Apigenin-7-O-glucoside; Peak 7: Apigenin-7-O-glucuronide; ${ }^{*}$ is DPPH.

Table 3. Inhibitory effect of the constituents on the sorbitol accumulation in rat lenses and inhibition type by active compound.

\begin{tabular}{cccc}
\hline Compounds & $\begin{array}{c}\text { Sorbitol Content (mg)/ } \\
\text { Lens Wet Weight (g) }\end{array}$ & $\begin{array}{c}\text { Inhibition } \\
\text { (\%) }\end{array}$ & $\begin{array}{c}\text { Inhibition Types } \\
\text { (References) }\end{array}$ \\
\hline Sorbitol free & $\begin{array}{c}\text { No detection } \\
\text { Control }\end{array}$ & - & - \\
\hline Quercetin a) & $0.47 \pm 0.04$ & $85.7 \pm 8.32$ & Noncompetitive [31] \\
Agrimoniin (AM) & $0.77 \pm 0.02$ & $47.6 \pm 1.34$ & Noncompetitive \\
Luteolin-7-O-glucuronide (LGN) & $0.12 \pm 0.01$ & $91.8 \pm 9.01$ & Noncompetitive \\
Quercitrin (QU) & $0.34 \pm 0.02$ & $76.9 \pm 5.32$ & Uncompetitive [29] \\
Luteolin (LT) & $0.12 \pm 0.01$ & $91.8 \pm 7.91$ & Mixed type [30] \\
Afzelin (AZ) & $0.10 \pm 0.01$ & $93.2 \pm 8.67$ & Noncompetitive \\
\hline
\end{tabular}

a) Quercetin was used as positive control; ${ }^{\text {b) }}$ [Number] is reference number. 


\subsection{Kinetic-Type RHAR Inhibition by the Active Compounds}

A kinetic study using DL-glyceraldehyde as a substrate at a concentration range of 1.0 to $25.0 \mathrm{mM}$ was performed to determine the type of inhibition that AM, LGN and AZ exhibited, which showed the highest activity. The kinetic analysis of RHAR inhibition shown in Figure 4 was conducted with AM, LGN and AZ using Lineweaver-Burk plots of 1 /velocity and 1/concentration of substrate. With the change of the concentration of the substrate DL-glyceraldehyde, the slopes obtained with the uninhibited enzyme and the three different concentrations of each compound were found to be parallel. The results showed that the inhibition of RHAR by AM, LGN and AZ were competitive and mixed-type. In addition, Lee et al., Ha et al., and Chethan et al. reported that QU, LT, and QC showed uncompetitive, mixed-type, and noncompetitive inhibition patterns, respectively, against RHAR (Table 3) [31-33].
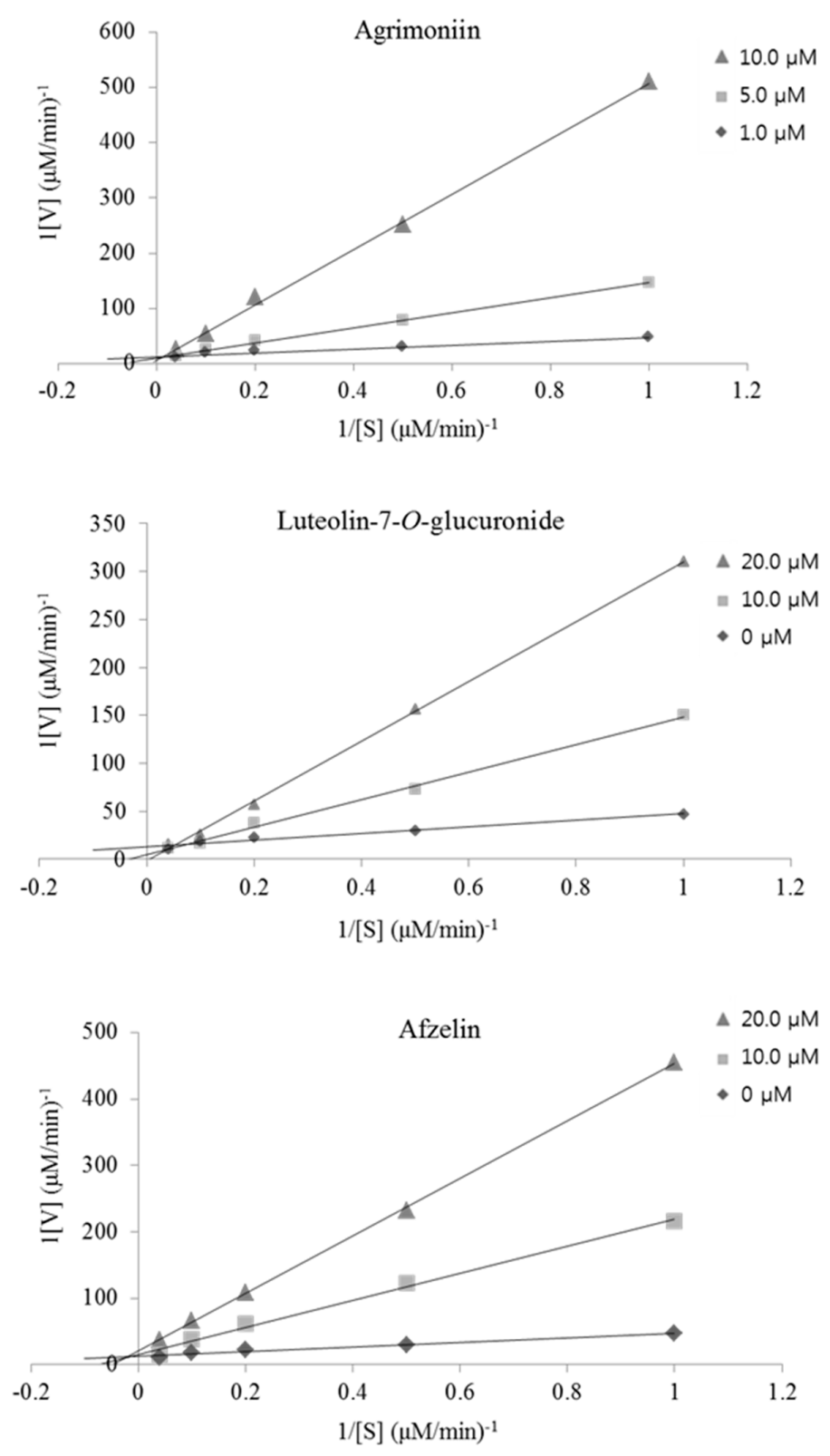

Figure 4. Lineweaver-Burk plots showing the reciprocal of the velocity $(1 / \mathrm{V})$ of recombinant rat lens aldose reductase versus the reciprocal of the substrate concentration $(1 / \mathrm{S})$ with $\mathrm{DL}_{\text {-glyceraldehyde as }}$ the substrate at concentrations of 1.0 to $25.0 \mathrm{mM}$. 


\subsection{Lens Culture and Intracellular Sorbitol Measurement}

We also investigated the effect of RLAR inhibitory compounds (including the known inhibitory compounds LT and AZ) on the sorbitol accumulation in isolated rat lens; the results are shown in Table 3. AM, LGN, QU, LT and AZ inhibited sorbitol accumulation by $47.6 \%, 91.8 \%, 76.9 \%, 91.8 \%$, and $93.2 \%$, respectively, at a concentration of $5.0 \mu \mathrm{g} / \mathrm{mL}$. In addition, QC as a positive control, which inhibits sorbitol accumulation in isolated rat lens by $85.7 \%$, reduced the sorbitol level in culture medium containing a high glucose concentration. These results indicated that RLAR inhibitors isolated from APE are effective in either preventing or slowing sugar cataract formation associated with diabetes.

\section{Discussion}

The results of the RLAR and DPPH revealed that all tested APEs have a potent inhibitory effect on RLAR and protect against oxidative stress (Figure 5); these results are shown in Table 1. In addition, the inhibitory effect of the $n-\mathrm{BuOH}$ fraction of APE on RLAR inhibition was comparable to that of the positive control TMS. In previous studies, VT, RT, HP, LT-7-O- $\beta$-D-glucopyranoside, $\mathrm{QC}$, tiliroside, LT, AP, and KP isolated from AP were analyzed by HPLC-UV and showed $\alpha$-glucosidase inhibitory activity, $\mathrm{ABTS}^{+}$radical scavenging activity, and hydroxyl radical scavenging activity [12]. QC-3-O- $\beta$-D-glucopyranoside, QC-3-O- $\alpha$-L-rhamnopyranoside, (2S,3S)-(-)-taxifolin-3-O- $\beta$-D-glucopyranoside, KP-3-O- $\alpha$-L-rhamnopyranoside, 1 -butanoyl-3,5dimethyl-phloroglucinyl-6-O-D-glucopyranoside, CT, tiliroside, AG, and agrimonolide in AP were established for characterization and simultaneous quantification by the HPLC-diode array detector-electrospray ionization mass spectrometry (MS)/MS method [10]. Kato et al successfully separated three new compounds and nine known compounds, including (-)-aromadendrin-3-O- $\beta$-D-glucopyranoside, desmethylagrimonolide-6-O- $\beta$-D-glucopyranoside, and 5,7-dihydroxy-2-propylchromone-7-O- $\beta$-D-glucopyranoside, agrimonolide-6-O-glucoside, takanechromone $\mathrm{C}, \mathrm{AT}, \mathrm{AZ}$, tiliroside, $\mathrm{LT}, \mathrm{QC}, \mathrm{IQC}$, and AGC from AP's aerial parts $\mathrm{MeOH}$ extract [11].

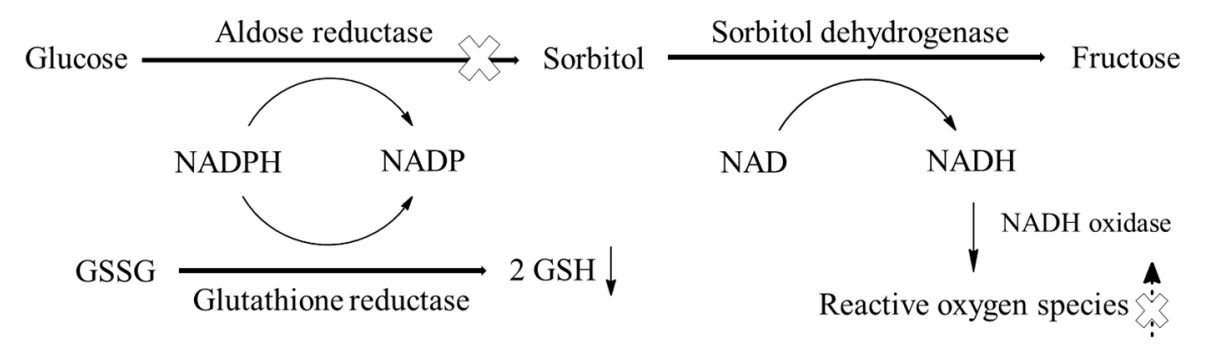

Inhibition points of Agrimonia pilosa and its constituents
\ Points of increasing or decreasing

Figure 5. Inhibition points of A. pilosa Ledeb and its constituents on polyol pathway. GSH: glutathione, GSSG: glutathione disulfide, NAD: nicotinamide adenine dinucleotide, NADH: oxidoreductase-induced nicotinamide adenine dinucleotide, NADP: nicotinamide adenine dinucleotide phosphate, NADPH: oxidoreductase-induced nicotinamide adenine dinucleotide phosphate.

Various flavonoid constituents were isolated as active compounds from AP. Based on the literature, we evaluated the effect of ten known flavonoids and isolated compounds from the $n$ - $\mathrm{BuOH}$ fraction of APE on RLAR. Among the compounds isolated, compound 4 was isolated for the first time from this plant and $\mathrm{AM}\left(\mathrm{IC}_{50}=1.6 \mu \mathrm{M}\right)$ was evaluated in RLAR for the first time. Except for AGN, all compounds showed a potent inhibitory effect, with $\mathrm{IC}_{50}$ values of 0.2-9.5 $\mu \mathrm{M}$. Among active compounds, LGN and QU had similar or higher activity than the positive control TMS. Previous flavonoid RLAR studies reported that LGC $(7.5 \mu \mathrm{M})$ [26], LGN $(3.1 \mu \mathrm{M})$, LT $(0.5 \mu \mathrm{M})$ [27], and AGC $(23.0 \mu \mathrm{M})$ [28] were 
isolated from plant sources. Matsuda et al. reported potent $\mathrm{IC}_{50}$ values as follows: QC $(2.2 \mu \mathrm{M})$, IQC $(4.5 \mu \mathrm{M}), \mathrm{HP}(3.0 \mu \mathrm{M})$, AG $(2.2 \mu \mathrm{M}), \mathrm{KP}(10.0 \mu \mathrm{M})$, and RT $(9.0 \mu \mathrm{M})$ [24]. QU had an $\mathrm{IC}_{50}$ value of $0.2 \mu \mathrm{M}$ [29]. These reported data were similar to our experimental data (shown in Table 2). The sorbitol accumulation was not significantly correlated with RLAR activity. AM, LGN, QU, LT, AZ, and QC showed different RLAR inhibitory effects ( $\mathrm{IC}_{50}$ values) as structures ( $\mathrm{QU}, 0.2 \mu \mathrm{M}>\mathrm{LT}, 0.6 \mu \mathrm{M}>\mathrm{LGN}$, $0.7 \mu \mathrm{M}>\mathrm{AZ}, 1.0 \mu \mathrm{M}>\mathrm{AM}, 1.6 \mu \mathrm{M}>\mathrm{QC}, 3.2 \mu \mathrm{M})$. On the other hand, high inhibition of sorbitol accumulation was observed in the following order: AZ (93.2\%), LGN (91.8\%) and LT (91.8\%), QC (85.7\%), QU (76.9\%), and AM (47.6\%). According to structures of flavonoids, different inhibitory effects were seen in vitro and ex vivo. Therefore, this result suggests that bioavailability may be affected by structures of flavonoids.

Based on these results, the RLAR inhibitory effect of flavonoid derivatives and the structure activity relationship (SAR) were investigated using the RLAR assay. RLAR inhibitory effects of flavonoid derivatives depend on the position and sugar type of the aromatic $\mathrm{A}$ and $\mathrm{C}$ ring at a catechol moiety. RT, QC, IQC, HP, and QU were isomers of flavonol and had rhamnoside, no sugar, galactoside, glucoside, and rutinoside, respectively, in the same position. However, these compounds showed different RLAR inhibitory effects and different $\mathrm{IC}_{50}$ values. RT showed $\mathrm{IC}_{50}$ values $15.5,20.0,25.5$, and 47.5 times higher than those of QC, HP, IQC, and QU, respectively. In addition, LT derivatives showed different RLAR inhibitory effects according to sugar types (LGN $>$ LT $>$ LGC). Flavone derivatives showed different patterns on SAR. AZ, AG, AGN, AG, KP, and AGN have no hydroxyl at the 4' position at a catechol moiety $\mathrm{B}$ ring, and showed lower activity than the flavonol structure. However, rhamnoside at the 3-position in the A ring of flavonol/flavone structure showed stronger activity than other sugar types, and glucuronide and glucoside at the $7^{\prime}$ position showed higher activity than glucoside at the $3^{\prime}$ and $7^{\prime}$ positions. A previous SAR study demonstrated that the inhibitory activity of flavonol/flavone was different according to $3^{\prime}, 4^{\prime}$-hydroxyl moiety in a catechol moiety at the B ring, and suggested that sugar type and hydroxyl moieties at the $3^{\prime}$ and $7^{\prime}$ position increased the activity of RLAR [26].

Offline DPPH-HPLC method is able to rapidly screen antioxidants from complex mixtures, especially for natural products with minimum sample preparation. Reduction or disappearance of the peak areas in the HPLC chromatogram certify potential antioxidant activity of the compounds, while there was no change of peak areas for compounds with no antioxidant activity after their reaction with DPPH. Zhang et al. reported that eighteen antioxidants were screened and identified from Pueraria lobata flowers by the offline DPPH-HPLC-MS/MS method [34] Moreover, seven antioxidant compounds in Eucommia ulmoides Olive were analyzed by offline DPPH-HPLC [35]. As shown in Figure 3, our offline DPPH-HPLC method results suggested that this method is a good strategy for selecting antioxidant compounds from crude plant extracts. Many studies were done for evaluating the antioxidant activities of flavonoids, which showed the ability to quench free radicals through several mechanisms, including the donation of electrons and hydrogen atoms, and chelate transition metals [36]. Thus, we evaluated the antioxidant activity of seven isolated compounds with offline DPPH-HPLC, as well as the DPPH radical scavenging activity of ten known flavonoids. The $n$-BuOH fraction of AP showed the capacity to scavenge DPPH radicals. In addition, AM, RT, LGC, LGN and QU showed potent DPPH inhibitory activity, with $\mathrm{IC}_{50}$ values of $13.0,66.8,71.5,80.6$, and $77.9 \mu \mathrm{M}$, respectively. Among ten known flavonoids, seven compounds (except for VT, AG, and AZ) exhibited potent DPPH inhibitory activity, with $\mathrm{IC}_{50}$ values of $65.9-156.3 \mu \mathrm{M}$, compared to L-ascorbic acid $(147.3 \mu \mathrm{M}$, Table 2). Although activity results of offline DPPH-HPLC and DPPH assay showed different activity patterns, we believe that the offline DPPH method can be very efficient and fast for screening antioxidant compounds from complex mixtures (natural products, food, or materials). 


\section{Materials and Methods}

\subsection{General}

${ }^{1} \mathrm{H}$ and ${ }^{13} \mathrm{C}$ NMR spectra and correlation 2D NMR spectra were obtained from a Bruker Avance DPX 400 (or 600) spectrometer. These spectra were obtained at operating frequencies of $400 \mathrm{MHz}$ $\left({ }^{1} \mathrm{H}\right)$ and 100 (or 150$) \mathrm{MHz}\left({ }^{13} \mathrm{C}\right)$ with $\mathrm{CD}_{3} \mathrm{OD},\left(\mathrm{CD}_{3}\right)_{2} \mathrm{SO},\left(\mathrm{CD}_{3}\right)_{2} \mathrm{CO}$, or $\mathrm{D}_{2} \mathrm{O}$ and TMS used as an internal standard; chemical shifts were reported in $\delta$ values. Isolated compounds were analyzed by electron ionization-MS in a low resolution-MS equipped with JMS-700. A semi prep-HPLC system for separation identification (recycling preparative LC908-C60, JAI, Tokyo, Japan) was used.

\subsection{Chemicals and Reagents}

L-Ascorbic acid, DPPH, NADPH, DL-glyceraldehyde dimer, TMG, glucose, and the reference compounds used in this study (CT, LT, QC, IQC, HP, AG, VT, KP, AS, and AZ) were purchased from Sigma-Aldrich (St. Louis, MO, USA). RHAR was purchased from Wako Pure Chemical Industries (Osaka, Japan). All other chemicals and reagents used were of analytical grade.

\subsection{Plant Materials}

Dried bark of AP was purchased at a local market in Yeongcheon, Gyeongsangbuk-do Province, Korea (June 2015). The AP was identified by Hyung Joon Chi at Seoul National University, and a voucher specimen (No. RIC-2015-0615) was deposited at the Regional Innovation Center, Hallym University, Korea.

\subsection{Extraction, Fractionation, and Isolation}

The dried bark of AP (10 kg) was extracted twice with methylene chloride $(50.0 \mathrm{~L} \times 2$ times) for $48 \mathrm{~h}$ at room temperature. The suspension was filtered and evaporated under reduced pressure at $40{ }^{\circ} \mathrm{C}$ to give methylene chloride extract (yield: $1.9 \%, 194.0 \mathrm{~g}$ ). The residue was extracted with APE. The suspension was filtered and evaporated under reduced pressure at $40{ }^{\circ} \mathrm{C}$ to give the APE (yield: $7.6 \%, 762.9 \mathrm{~g}$ ). This extract was suspended in distilled water and then successively partitioned with EtOAc, $n$-BuOH and water to yield EtOAc $(17.2 \%, 110.0 \mathrm{~g}), n$-BuOH $(20.6 \%, 132.0 \mathrm{~g})$ and water fractions $(59.5 \%, 381.3 \mathrm{~g})$, respectively. These fractions were concentrated to dryness by rotary evaporation at $40{ }^{\circ} \mathrm{C}$, while the water fraction was freeze-dried. The $n$-BuOH fraction showed strong inhibitory activity against RLAR. Thus, the $n$ - $\mathrm{BuOH}$ fraction was applied to an open glass column packed with Diaion $\mathrm{HP}-20$ with $\mathrm{MeOH}-\mathrm{H}_{2} \mathrm{O}$ in a gradient of $30 \%-100 \% \mathrm{MeOH}$, thereby yielding 15 sub-fractions (HP-S1 to HP-S15). It was then eluted with water to wash any sugars or impure components. Fraction HP-S8 (200.0 mg) was purified to yield compound 1 (69.3 mg) and compound $2(30.3 \mathrm{mg})$ by recycle HPLC with a gradient system from $30 \%-35 \% \mathrm{MeOH}$. Other fractions obtained from Diaion HP-20 were applied to a Sephadex LH-20 column $(90 \mathrm{~cm} \times 3 \mathrm{~cm}$, internal diameter). Fraction HP-S9 (888.6 mg) was separated with 70\% MeOH to obtain compound 3 (96.1 mg) and compound 4 (150.5 mg). Fraction HP-S11 (797.1 mg) was separated with a $60 \% \mathrm{MeOH}$ system to obtain compound 5 (11.6 mg) and compound 6 (21.3 mg). Fraction HP-S12 (465.9 mg) was isolated with a $100 \% \mathrm{MeOH}$ system to yield compound 7 (251.6 mg).

\subsection{Preparation of Aldose Reductase}

Crude RLAR was prepared as follows: lenses weighing 250-280 g were removed from Sprague-Dawley rats and frozen at $-70{ }^{\circ} \mathrm{C}$ until use. This was approved by the University of Hallym Animal Care and Use Committee (registration number: Hallym 2015-06-08). Non-cataractous transparent lenses were pooled and a homogenate was prepared in $0.1 \mathrm{M}$ phosphate-buffered saline ( $\mathrm{pH}$ 6.2). RLAR homogenate was then centrifuged at $10,000 \times g$ for 20 min at $4{ }^{\circ} \mathrm{C}$ in a refrigerated 
centrifuge. The supernatant was collected and used as the RLAR. All procedures were carried out at $4{ }^{\circ} \mathrm{C}[37]$.

\subsection{Determination of RLAR Inhibition In Vitro}

RLAR activity was assayed spectrophotometrically by measuring the decrease in the absorption of NADPH at $340 \mathrm{~nm}$ over a 3-min period using DL-glyceraldehyde as the substrate. Each $1.0 \mathrm{~mL}$ cuvette contained equal units of the enzyme, $0.10 \mathrm{M}$ potassium phosphate buffer ( $\mathrm{pH}$ 6.2), $1.6 \mathrm{mM}$ $\mathrm{NADPH}, 25 \mathrm{mM}_{\mathrm{DL}}$-glyceraldehyde (the substrate), and an inhibitor or dimethyl sulfoxide (DMSO). The inhibition of RLAR $(\%)$ was calculated with the following equation: $[1-(\Delta \mathrm{A}$ sample $/ \mathrm{min})-(\Delta \mathrm{A}$ blank $/ \mathrm{min}) /(\Delta \mathrm{A}$ control $/ \mathrm{min})-(\Delta \mathrm{A}$ blank $/ \mathrm{min})] \times 100 \%$, where $\Delta \mathrm{A}$ sample $/ \mathrm{min}$ is the reduction of absorbance for $3 \mathrm{~min}$ with reaction solution, the test sample, and substrate, and $\Delta \mathrm{A}$ control $/ \mathrm{min}$ is the same but with DMSO instead of the test sample [38].

\subsection{HPLC Analysis}

The sample was analyzed using an Agilent Technologies modular model 1200 system with a vacuum degasser (G1322A), a quaternary pump (G1311A), an auto-sampler (G1329A), a thermo-statted column compartment (G1316A), and a variable wavelength detector (VWD, G1314D) system. The separation was achieved on an Eclipse XDB-phenyl column $(150 \mathrm{~mm} \times 4.6 \mathrm{~mm}, 3.5 \mu \mathrm{m})$ maintained at $30{ }^{\circ} \mathrm{C}$. The elution solvents were $0.1 \%$ trifluoroacetic acid (A) and $\mathrm{MeOH}(\mathrm{B})$ with the following gradient: $20 \%-30 \%$ B (0-3 $\mathrm{min}), 30 \%-40 \%$ B (3-10 $\mathrm{min}), 40 \%-50 \%$ B (10-20 $\mathrm{min}), 50 \%-60 \%$ B (25-35 min), 60\%-100\% B ( $25-35 \mathrm{~min}), 100 \%-100 \%$ B (35-38 min), 100\%-20\% B (38-40 $\mathrm{min})$, and $20 \%-20 \%$ B (40-45 min). Injection volume was $10 \mu \mathrm{L}$ (sample concentration: $1 \mathrm{mg} / \mathrm{mL}$ ) and UV wavelength was $254 \mathrm{~nm}$.

\subsection{Evaluation of DPPH Radical Scavenging Capacity}

The stable free radical was used to determine the free radical-scavenging activity of the extracts [39]. Briefly, a $0.32 \mathrm{mM}$ solution of DPPH in $\mathrm{MeOH}$ was prepared, and $180 \mu \mathrm{L}$ of this solution was mixed with $30 \mu \mathrm{L}$ of each sample at concentrations of $0.05-1.0 \mathrm{mg} / \mathrm{mL}$ in DMSO. After $20 \mathrm{~min}$ of incubation in the darkroom, the decrease in the absorbance of the solution was measured at $570 \mathrm{~nm}$ on a microplate reader (EL800 Universal Microplate reader, Bio-Tek instruments, Winooski, VT, USA). DPPH inhibitory activity was expressed as the percentage inhibition (\%) of DPPH in the aforementioned assay system, and was calculated as $\left[1-\left(\mathrm{A}_{\text {sample }}-\mathrm{A}_{\text {blank }} / \mathrm{A}_{\text {control }}-\mathrm{A}_{\text {blank }}\right)\right] \times 100 \%$, where $\mathrm{A}_{\text {control }}$ is the absorbance of DPPH solution $(180 \mu \mathrm{L})$ with methanol $(30 \mu \mathrm{L})$; $A_{\text {blank }}$ is the absorbance of distilled water $(180 \mu \mathrm{L})$ with methanol $(30 \mu \mathrm{L})$; $\mathrm{A}_{\text {sample }}$ is the absorbance of DPPH solution $(180 \mu \mathrm{L})$ with sample solution $(30 \mu \mathrm{L})$.

\subsection{OffLine DPPH HPLC Assay}

The offline DPPH HPLC assay was performed by modifying a previously-described protocol [40]. Thirty microliters $(20 \mathrm{mg} / \mathrm{mL}$ in $\mathrm{MeOH})$ of the $n$ - $\mathrm{BuOH}$ fraction from APE were mixed with $180 \mu \mathrm{L}$ prepared DPPH solution $(0.32 \mathrm{mM})$. The mixture was incubated in the dark for $20 \mathrm{~min}$, then filtered through a $0.45-\mu \mathrm{m}$ filter for HPLC analysis. The $n-\mathrm{BuOH}(20 \mathrm{mg} / \mathrm{mL}$ in $\mathrm{MeOH})$ was used as a control. The extent of peak decrease is expressed as a quantitative reduction. 


\subsection{Determination of Inhibition-Type of RHAR by Active Compound}

Reaction mixtures consisted of $0.1 \mathrm{M}$ potassium phosphate, $1.6 \mathrm{mM} \mathrm{NADPH}$, and $2 \mathrm{mM}$ of RHAR with varied concentrations of substrate $\mathrm{DL}$-glyceraldehyde and AR inhibitor in a total volume of $600 \mu \mathrm{L}$. Concentrations ranged from 0 to $25 \mathrm{mM}$ for DL-glyceraldehyde and from 0 to $20 \mu \mathrm{M}$ for the active compound. RHAR activity was assayed by measuring the decrease in absorption of NADPH after substrate addition at $340 \mathrm{~nm}$ using a Bio Tek Power Wave XS spectrophotometer (Bio Tek Instruments, Winooski, VT, USA) [41].

\subsection{Lens Culture and Intracellular Sorbitol Measurement}

Lenses isolated from 10-week-old Sprague-Dawley rats using the registration number mentioned in the section of 4.5 were cultured for $6 \mathrm{~d}$ in TC-199 medium that contained $15 \%$ fetal bovine serum, 100 units $/ \mathrm{mL}$ penicillin, and $0.1 \mathrm{mg} / \mathrm{mL}$ streptomycin, under sterile conditions and an atmosphere of $5 \% \mathrm{CO}_{2}$ and $95 \%$ air at $37^{\circ} \mathrm{C}$. Samples were dissolved in DMSO. The lenses were divided into three groups and cultured in medium containing $30 \mathrm{mM}$ glucose and RLAR-active compounds. Each lens was placed in a well containing $2.0 \mathrm{~mL}$ of medium. Sorbitol was determined by HPLC using the methods mentioned in the section of 4.7 after its derivatization by reaction with benzoic acid to a fluorescent compound [42].

\subsection{Statistical Analysis}

Inhibition rates were calculated as percentages (\%) with respect to the control value, and the $\mathrm{IC}_{50}$ value was defined as the concentration at which $50 \%$ inhibition occurred. Data are expressed as mean values \pm standard deviation of triplicate experiments.

\section{Conclusions}

In summary, seven compounds isolated from the $n$ - $\mathrm{BuOH}$ fraction of the APE and ten flavonoids known as ingredients of AP were evaluated for RLAR inhibitory activity and DPPH radical scavenging activity. Additionally, antioxidant compounds in the $n-\mathrm{BuOH}$ fraction of APE were investigated with a DPPH offline HPLC assay. Of the compounds tested, AM, LGN, QU, LT, and AZ showed strong inhibitory activity against RLAR and sorbitol accumulation. Consequently, we conclude that APE and its constituents may play partial roles in RLAR and oxidative radical inhibition. Our results suggest that AP may potentially be used as a herbal drug to treat diabetic complications.

Supplementary Materials: Supplementary materials can be found at www.mdpi.com/1422-0067/18/2/379/s1.

Acknowledgments: This work was supported by Korea Institute of Planning and Evaluation for Technology in Food, Agriculture, Forestry and Fisheries (IPET) through High Value-Added Food Technology Development Program, funded by the Ministry of Agriculture, Food and Rural Affairs (MAFRA) (115001-3).

Author Contributions: Soon Sung Lim and Hong-Won Suh designed the experiments; Set Byeol Kim prepared the extract sample, isolated its compounds, and prepared aldose reductase and DPPH assays; Seung Hwan Hwang conducted the structure identification and data analysis; Seung Hwan Hwang wrote the first draft, and Soon Sung Lim revised the manuscript; All the authors read and approved the final manuscript and all authors name added in manuscript.

Conflicts of Interest: The authors declare no conflict of interest. 


\section{Abbreviations}

$\begin{array}{ll}\text { AR } & \text { aldose reductase } \\ \text { NADPH } & \text { nicotinamide adenine dinucleotide phosphate } \\ \text { NADH } & \text { nicotinamide adenine dinucleotide } \\ \text { CT } & \text { catechin } \\ \text { AP } & \text { Agrimonia pilosa Ledeb } \\ \text { LT } & \text { luteolin } \\ \text { QC } & \text { quercetin } \\ \text { IQC } & \text { isoquercetin } \\ \text { HP } & \text { hyperin } \\ \text { AG } & \text { apigenin } \\ \text { VT } & \text { vitexin } \\ \text { KP } & \text { kaempferol } \\ \text { AS } & \text { astragalin } \\ \text { AZ } & \text { afzelin } \\ \text { RLAR } & \text { rat lens aldose reductase } \\ \text { APE } & \text { Agrimonia pilosa } 50 \% \text { methanol (MeOH) extract } \\ \text { RHAR } & \text { recombinant human aldose reductase } \\ \text { ICs } & \text { isolated compounds isolated from Agrimonia pilosa } \\ \text { KNCs } & \text { known compounds isolated from Agrimonia pilosa } \\ \text { TMG } & \text { tetramethylene glutaric acid } \\ \text { PAR } & \text { peak area reduction } \\ \text { CH }{ }_{2} \mathrm{Cl}{ }_{2} & \text { methylene chloride } \\ \text { EtOAc } & \text { ethyl acetate } \\ n \text {-BuOH } & n \text {-butanol } \\ \text { DPPH } & \text { 1,1-diphenyl-2-picrylhydrazyl } \\ & \end{array}$

\section{References}

1. Fatmawati, S.; Kurashiki, K.; Takeno, S.; Kim, Y.U.; Shimizu, K.; Sato, M.; Imaizumi, K.; Takahashi, K.; Kamiya, S.; Kaneko, S.; et al. The inhibitory effect on aldose reductase by an extract of Ganoderma lucidum. Phytother. Res. 2009, 23, 28-32. [CrossRef] [PubMed]

2. Peyroux, J.; Sternberg, M. Advanced glycation endproducts (AGEs): Pharmacological inhibition in diabetes. Pathol. Biol. 2006, 54, 405-419. [CrossRef] [PubMed]

3. Abdollahi, M.; Ranjbar, A.; Shadnia, S.; Nikfar, S.; Rezaie, A. Pesticides and oxidative stress: A review. Med. Sci. Monit. 2004, 10, 141-147.

4. Sundaram, R.K.; Bhaskar, A.; Vijayalingam, S.; Viswanathan, M.; Mohan, R.; Shanmugasundaram, K.R. Antioxidant status and lipid peroxidation in type II diabetes mellitus with and without complications. Clin. Sci. 1996, 90, 255-260. [CrossRef] [PubMed]

5. Matough, F.A.; Budin, S.B.; Hamid, Z.A.; Alwahaibi, N.; Mohamed, J. The role of oxidative stress and antioxidants in diabetic complications. Sultan Qaboos Univ. Med. J. 2012, 12, 5-18. [CrossRef] [PubMed]

6. Zhu, L.; Tana, J.; Wang, B.; Hea, R.; Liuc, Y.; Zhenga, C. Antioxidant activities of aqueous extract from Agrimonia pilosa Ledeb and its fractions. Chem. Biodivers. 2009, 6, 1716-1726. [CrossRef] [PubMed]

7. Kim, J.J.; Jiang, J.; Shim, D.W.; Kwon, S.C.; Kim, T.J.; Ye, S.K.; Kim, M.K.; Shin, Y.K.; Koppula, S.; Kang, T.B.; et al. Anti-inflammatory and anti-allergic effects of Agrimonia pilosa Ledeb extract on murine cell lines and OVA-induced airway inflammation. J. Ethnopharmacol. 2012, 140, 213-221. [CrossRef] [PubMed]

8. Jung, M.K.; Park, M.S. Acetylcholinesterase inhibition by flavonoids from Agrimonia pilosa. Molecules 2007, 12, 2130-2139. [CrossRef] [PubMed]

9. An, R.B.; Kim, H.C.; Jeong, G.S.; Oh, S.H.; Oh, H.; Kim, Y.C. Constituents of the aerial parts of Agrimonia pilosa. Nat. Prod. Sci. 2005, 11, 196-198.

10. Jiang, Q.; Ma, J.; Wang, Y.; Ding, L.; Chen, L.; Qiu, F. Simultaneous determination of nine major constituents in Agrimonia pilosa Ledeb. by HPLC-DAD-ESI-MS/MS. Anal. Methods 2014, 6, 4373-4379. [CrossRef]

11. Kato, H.; Li, W.; Koike, M.; Wang, Y.; Koike, K. Phenolic glycosides from Agrimonia pilosa. Phytochemistry 2010, 71, 1925-1929. [CrossRef] [PubMed] 
12. Liu, X.; Zhu, L.; Tan, J.; Zhou, X.; Xiao, L.; Yang, X.; Wang, B. Glucosidase inhibitory activity and antioxidant activity of flavonoid compound and triterpenoid compound from Agrimonia pilosa Ledeb. BMC Complement. Altern. Med. 2014, 14, 12. [CrossRef] [PubMed]

13. Veeresham, C.; Rama Rao, A.; Asres, K. Aldose reductase inhibitors of plant origin. Phytother. Res. 2013, 28, 317-333. [CrossRef] [PubMed]

14. Jung, H.A.; Isslam, M.D.N.; Kwon, Y.S.; Jin, S.E.; Son, Y.K.; Park, J.J.; Sohn, H.S.; Choi, J.S. Extraction and identification of three major aldose reductase inhibitors from Artemisia montana. Food Chem. Toxicol. 2011, 49, 376-384. [CrossRef] [PubMed]

15. Zeng, H.; Liu, Q.; Wang, M.; Jiang, M.; Jiang, S.; Zhang, L.; He, L.; Wang, J.; Chen, X. Target-guided separation of antioxidants from Semen cassia via off-line two-dimensional high-speed counter-current chromatography combined with complexation and extrusion elution mode. J. Chromatogr. B 2015, 1001, 58-65. [CrossRef] [PubMed]

16. Tang, D.; Li, H.J.; Chen, J.; Guo, C.W.; Li, P. Rapid and simple method for screening of natural antioxidants from Chinese herb Flos Lonicerae japonicae by DPPH-HPLC-DAD-TOF/MS. J. Sep. Sci. 2008, 31, 3519-3526. [CrossRef] [PubMed]

17. Olennikov, D.N.; Kashchenko, N.I.; Chirikova, N.K.; Kuzmina, S.S. Phenolic profile of Potentilla anserina L. (Rosaceae) herb of Siberian origin and development of a rapid method for simultaneous determination of major phenolics in P. anserina pharmaceutical products by microcolumn RP-HPLC-UV. Molecules 2015, 20, 224-248. [CrossRef] [PubMed]

18. Fathiazad, F.; Delazar, A.; Amiri, R.; Sarker, S.D. Extraction of flavonoids and quantification of rutin from waste tobacco leaves. Iran. J. Pharm. Res. 2006, 3, 222-227.

19. Lee, S.H.; Choi, M.J.; Choi, J.M.; Lee, S.; Kim, H.Y.; Cho, E.J. Flavonoids from Taraxacum coreanum protect from radical-induced oxidative damage. J. Med. Plants Res. 2012, 6, 5377-5384.

20. Lu, Y.; Foo, L.Y. Flavonoid and phenolic glycosides from Salvia officinalis. Phytochemistry 2000, 55, $263-267$. [CrossRef]

21. Lu, Y.; Foo, L.Y. Identiücation and quantiücation of major polyphenols in apple pomace. Food Chem. 1997, 59, 187-194. [CrossRef]

22. Pieroni, A.; Heimler, D.; Pieters, L.; van Poel, B.; Vlietnick, A.J. In vitro anti-complementary activity of flavonoids from olive (Olea europaea L.) leaves. Pharmazie 1996, 51, 765-768. [PubMed]

23. Baris, O.; Karadayi, M.; Yanmis, D.; Guvenalp, Z.; Bal, T.; Gulluce, M. Isolation of 3 flavonoids from Mentha longifolia (L.) Hudson sucsp. longifolia and determination of their genotoxic potentials by using the E. coli WP2 test system. J. Food Sci. 2011, 76, 212-217.

24. Matsuda, H.; Morikawa, T.; Toguchida, I.; Yoshikawa, M. Structural requirements of flavonoids and related compounds for aldose reductase inhibitory activity. Chem. Pharm. Bull. 2002, 50, 788-795. [CrossRef] [PubMed]

25. Naeem, S.; Hylands, P.; Barlow, D. Construction of an Indonesian herbal constituents database and its use in Random Forest modelling in a search for inhibitors of aldose reductase. Bioorg. Med. Chem. 2012, 20, 1251-1258. [CrossRef] [PubMed]

26. Li, H.M.; Hwang, S.H.; Kang, B.G.; Hong, J.S.; Lim, S.S. Inhibitory effects of Colocasia esculenta (L.) Schott constituents on aldose reductase. Molecules 2014, 19, 13212-13224. [CrossRef] [PubMed]

27. Yoshikawa, M.; Morikawa, T.; Murakami, T.; Toguchida, I.; Harima, S.; Matsuda, H. Medical flowers, I. Aldose reductase inhibitors and three new eudesmane-type sesquiterpenes, kikkanols A, B, and C, from the flowers of Chrysanthemum indicum L. Chem. Pharm. Bull. 1999, 47, 340-345. [CrossRef] [PubMed]

28. Matsuda, H.; Morikawa, T.; Toguchida, I.; Harima, S.; Yoshikawa, M. Medicinal flowers. VI. Absolute stereostructures of two new flavanone glycosides and a phenylbutanoid glycoside from the Flowers of Chrysanthemum indicum L.: Their inhibitory activities for rat lens aldose reductase. Chem. Pharm. Bull. 2002, 50, 972-975. [CrossRef] [PubMed]

29. Yoshikawa, M.; Shimada, H.; Nishida, N.; Li, Y.; Toguchida, I.; Yamahara, J.; Matsuda, H. Antidiabetic principles of natural medicines. II. aldose reductase and $\alpha$-glucosidase inhibitors from Brazilian natural medicine, the leaves of Myrcia multiflora DC. (Myrtacae): Structures of myrciacitrins I and II and myrciaphenones A and B. Chem. Pharm. Bull. 1998, 46, 113-119. [CrossRef] [PubMed] 
30. Mok, S.Y.; Lee, S.H. Identification of flavonoids and flavonoid rhamnosides from Rhododendron mucronulatum for albiflorum and their inhibitory activities against aldose reductase. Food Chem. 2013, 136, 969-974. [CrossRef] [PubMed]

31. Lee, E.H.; Song, D.G.; Lee, J.Y.; Pan, C.H.; Um, B.H.; Jung, S.H. Flavonoids from the leaves of Thuja orientalis inhibit the aldose reductase and the formation of advanced glycation endproducts. J. Korean Soc. Appl. Biol. Chem. 2009, 52, 448-455. [CrossRef]

32. Ha, T.J.; Lee, J.H.; Lee, M.H.; Lee, B.W.; Kwon, H.S.; Park, C.H.; Shim, K.B.; Kim, H.T.; Baek, I.Y.; Jang, D.S. Isolation and identification of phenolic compounds from the seeds of Perilla frutescens (L.) and their inhibitory activities against $\alpha$-glucosidase and aldose reductase. Food Chem. 2012, 135, 1397-1403. [CrossRef] [PubMed]

33. Chethan, S.; Dharmesh, S.M.; Malleshi, N.G. Inhibition of aldose reductase from cataracted eye lenses by finger millet (Eleusine coracana) polyphenols. Bioorg. Med. Chem. 2008, 16, 10085-10090. [CrossRef] [PubMed]

34. Zhang, Y.P.; Shi, S.Y.; Xiong, X.; Chen, X.Q.; Peng, M.J. Comparative evaluation of three methods based on high-performance liquid chromatography analysis combined with a 2,2'-diphenyl-1-picrylhydrazyl assay for the rapid screening of antioxidants from Pueraria lobate flowers. Anal. Bioanal. Chem. 2012, 402, 2965-2976. [CrossRef] [PubMed]

35. Dia, X.; Huang, Q.H.; Zhou, B.; Gong, Z.; Liu, Z.; Shi, S. Preparative isolation and purification of seven main antioxidants from Eucommia ulmoides Oliv. (Du-zhong) leaves using HSCCC guided by DPPH-HPLC experiment. Food Chem. 2013, 139, 563-570.

36. Agati, G.; Azzarello, E.; Pollastri, S.; Tattini, M. Flavonoids as antioxidants in plants: Location and functional significance. Plant Sci. 2012, 196, 67-76. [CrossRef] [PubMed]

37. Yoon, H.N.; Lee, M.Y.; Kim, J.K.; Suh, H.W.; Lim, S.S. Aldose reductase inhibitory compounds from Xanthium strumarium. Arch. Pharm. Res. 2013, 36, 1090-1095. [CrossRef] [PubMed]

38. Peak, J.H.; Lim, S.S. Preparative isolation of aldose reductase inhibitory compounds from Nardostachys chinensis by elution-extrusion counter-current chromatography. Arch. Pharm. Res. 2014, 37, 1271-1279. [CrossRef] [PubMed]

39. Choi, C.W.; Kim, S.C.; Hwang, S.S.; Choi, B.K.; Ahn, H.J.; Lee, M.Y.; Park, S.H.; Kim, S.K. Antioxidant activity and free radical scavenging capacity between Korean medicinal plants and flavonoids by assay-guided comparison. Plant Sci. 2002, 163, 1161-1168. [CrossRef]

40. Shi, S.Y.; Ma, Y.J.; Zhang, Y.P.; Liu, L.L.; Liu, Q.; Peng, M.J.; Xiong, X. Systematic separation and purification of 18 antioxidants from Pueraria lobata flower using HSCCC target-guided by DPPH-HPLC experiment. Sep. Purif. Technol. 2012, 89, 225-233. [CrossRef]

41. Kim, T.H.; Kim, J.K.; Kang, Y.H.; Lee, J.Y.; Kang, I.J.; Lim, S.S. Aldose reductase inhibitory activity of compounds from Zea mays L. Biomed. Res. Int. 2013, 2013, 8. [CrossRef] [PubMed]

42. Lee, Y.S.; Kim, S.H.; Jung, S.H.; Kim, J.K.; Pan, C.H.; Lim, S.S. Aldose reductase inhibitory compounds from Glycyrrhiza uralensis. Biol. Pharm. Bull. 2010, 33, 917-921. [CrossRef] [PubMed]

(C) 2017 by the authors; licensee MDPI, Basel, Switzerland. This article is an open access article distributed under the terms and conditions of the Creative Commons Attribution (CC BY) license (http://creativecommons.org/licenses/by/4.0/). 